\title{
Mobile Technologies' Utilization and Competency among College Students
}

\author{
Mokhtar Hood Bindhorob ${ }^{1}$ \\ Department of Education Technology \\ College of Educational Studies \\ University Putra Malaysia
}

\author{
Khaled Salmen Aljaaidi ${ }^{2}$ \\ Department of Accounting \\ College of Business Administration \\ Prince Sattam bin Abdulaziz University
}

\begin{abstract}
The focus of this study is to (1) determine the level of mobile technologies' utilization and competency and (2) report separately the level of basic operation, communication and collaboration, information Seeking, digital citizenship and creativity and innovation skills in mobile technologies among first year undergraduate students in College of Computer Science and Information Technology at Hadhramout University. The sample size consists of 148 freshmen students. Using the descriptive statistical analysis, the results of this study reveal that undergraduates in College of Computer Science and Information Technology have highly utilized mobile technologies. It was also figured out that they were extremely capable to use these devices. Moreover, it was revealed that undergraduates' competency and utilization levels were so high in communication purpose due to certain social and educational reasons. Due to the results of the study, wider and greater implication of this method in College of Computer Science and Information Technology and other colleges at Hadhramout University is recommended along with the activation of the university apps.
\end{abstract}

Keywords-Mobile technologies; utilization; competency; college students

\section{BACKGROUND OF THE STUDY}

World Bank Institute reported that the number of smart phone users in 2010 had increased to 5 billion as compared to only 700 million users in early year of 2000, which indicates that the increase of users in percentages would be more than $70 \%$ of the world population in future. With that figure, it would absolutely be doubted whether underdeveloped country like Yemen is on the race with other developed countries or not. A report from [15] declared that the number of mobile customers in Yemen increased in December 2015 to reach to 16.88 million users. In this same report, it is declared that the basic mobile phone facilities were steadily becoming familiar with mobile networks reaching about 90 percent of the population. Moreover, it is discovered that the number of mobile phone subscriptions in Yemen had notably raised to five-fold from 3 million in 2006 to 16 million in 2016, resulting to 56.9-percentage penetration for a population of about 28 million. Furthermore, the report detailed that the claim for internet-enabled $3 \mathrm{G}$ facilities was increasing as Yemenis started switching from using basic mobile phones to smartphones and computers such as laptops and tablets [1].

This growth is expected to have an effect of further learning evolution, particularly in higher education institutions (HEI). These institutions will be going through quick changes, especially during the next 10 years due to this rapid growth [15]. Moreover, it is obvious that ubiquitous information systems are altering the creation and dissemination of information in new ways, producing opportunities in all aspects of society [16] [11]. In their study; [13] consider mobile learning as a major evolution in HEI learning sector where students and professors are more enlightened in technology due to its existence. On the other hand, the author in [17], revealed that HEI has extremely modified the reason of the continuous development of mobile computing devices and internet resources. The author in [14] stated that HEI students might be ready to accept m learning sooner than K-12 students do because more college students have their own mobile devices. The author in [15], concluded in their survey, which is conducted in Republic of Yemen, that students in HEI have positive attitude towards the use of e-learning and m-learning. They also discovered that they are familiar with the use of smartphone facilities in daily activities.

However, the availability of mobile devices does not necessary ensure high utilization of the devices among students particularly in education field. We must first assess the students' readiness for mobile learning [2] [5] [6] with regard to these issues. The author in [15] discovered that despite the familiarity of e learning and $\mathrm{m}$ learning among undergraduate students in Yemen, HEI students do not use smartphones for learning actively. Therefore, the aims of this study are to (1) determine the level of mobile technologies' utilization among first year undergraduate students, (2) identify the level of mobile technologies' competency among first year undergraduate students, and (3) report separately the level of basic operation, communication and collaboration, information Seeking, digital citizenship and creativity and innovation skills in mobile technologies competency.

The importance of this study stems out of the fact that mobile learning through mobile technologies will be the centre focus of this study because Yemen is one of the countries that experiencing a scarcity of mobile technology resources, where the utilization of mobile technologies is known to be quite limited. Moreover, this study also attempts to reveal the level of mobile technologies utilisation among the students. Hence, it is hoped that the results of this study will later bring on benefits to the higher authority of the university, to improve the existing learning conditions. Another worth noted point is that this study would later on be a good reference to other future studies within the same context in Yemen or in any Arabic country. With very little searched topics in the field of 
integrated technologies especially in mobile technologies adoption, it is vital and essential to tackle this topic.

\section{RESEARCH METHODOLOGY}

\section{A. Population and Samples}

In a country like Yemen where integration of technology is in an infant stage, it becomes very distinguished, remarkable and of a great interest to have a fully equipped faculty. In college of computer science and information technology, technologies like mobile devices are extensively applied. Therefore, this faculty have been chosen for this study to investigate the influence of competency of mobile technologies among the undergraduate students on their frequent utilization of these devices. Another possible reason is that majority numbers of staff in this faculty possesses an outstanding knowledge and are among specialists in the field of computer science and information technologies. All of the staff in this faculty is continuously trying to innovate their teaching method in line with the use of current and available technologies.

Besides, using mobile devices like laptops, tablets and mobiles inside classes are compulsory for all students in this faculty to facilitate the learning process. Majority of the given task need to be done outside classes, purposely to let the students experience the mobile learning approaches. More precisely, all first year students in Computer Science and Information Technology Departments in this faculty are selected to participate in the study due to some of characteristics found in them. First, these students are newly introduced to new purposes of using these devices as stated before and uses of mobile technologies especially learning, studying and research purposes. Moreover, they are studying subjects with a relation to the topic of this study like; communication skills, learning skills, thinking skills and searching skills in the second semester of their first year. They are even studying about theory of computation. Hence, they possess at least the basis knowledge of M-Learning in general. Moreover, the choice of time which is the second semester when it is applicable to check whether being in this department studying these subjects and knowing the new purposes changed the way they utilize these devices.

In addition to that, the researcher wants to check whether the availability of these technologies and the allowance of using them will affect the way these undergraduates perceive the technologies and use them. Due to the above-mentioned reasons, all of the first year undergraduates were selected as the study sample, which means a census population was chosen. This also means that no sampling was done for this study. Moreover, the selection of the sample of this study is supported by study conducted by (Dawson, 2007; Saunders et al., 2007; Zikmund et al., 2010) who states that census is the most suitable for this research since participants are so rare and distinguished. They are of great interest to the researcher since they have owned previously stated features.

\section{B. Instrument}

Due to the characteristics of questionnaire survey which offers cheap and time saving, hence the instrument is distributed with online and offline method. Moreover, the results of the survey questionnaire can be generalized [4]. The instrument used in this study is divided into three sections: Section 1: The demographic information, Section 2: the utilization of mobile technologies, and Section 3: the competency factor. Table I presents the summary of the survey instruments sections.

1) Demographic information: The items are developed by the researcher to get respondent's personal information particularly on the history of these technologies. There are four items or questions in this section. All of them are closeended questions. All these items are asking about personal information like, departments (CS or IT), gender, and age. Etc.

2) Utilization of mobile technologies: This part of the instrument is adopted from [12] which quoted from [7]. This section contains 40 items which divided into six sub sections of: i) basic information uses, ii) communication uses, iii) collaboration uses, iv) information seeking uses, v) digital citizenship uses, and vi) creativity and innovation uses. The aim of this section is to explore the undergraduate students' level of utilization of mobile technologies. In other words, it will reveal how frequently they utilized the mobile application in related to M-Learning. Each item in every subsection is measured through five Likert scale which represented by (1) to (5), (1) never, rarely (Once or twice), (2) sometimes $(2-3$ times a week), (3) often $4-6$ times a week and (5) almost every day. Table II shows the six subsections in the utilization of mobile technologies section with the number of items for each section.

TABLE I. SECTIONS IN THE QUESTIONNAIRE

\begin{tabular}{|l|l|l|}
\hline Section & Aspect measure & No. of items \\
\hline Section 1 & Demographic information & 5 \\
\hline Section 2 & Utilization of mobile technologies & 40 \\
\hline Section 3 & Competency factor & 40 \\
\hline
\end{tabular}

TABLE II. SUBSECTIONS OR DIMENSIONS WITH ITEMS OF MOBILE TECHNOLOGIES UTILIZATION

\begin{tabular}{|l|l|}
\hline Name of subsection & No. of items \\
\hline Basic operation uses & 7 \\
\hline Communication uses & 9 \\
\hline Collaboration uses & 3 \\
\hline Information seeking uses & 7 \\
\hline Digital citizenship uses & 9 \\
\hline Creativity and innovation uses & 5 \\
\hline
\end{tabular}




\section{Data Collection}

There are few challenges that need to be dealt with during the data collection phase. Despite the easiness of distributing questionnaires online, it is notably hard to administer it. Therefore, the researcher prefers to distribute the questionnaires in a collective way. Having a good relationship with lecturers was another reason why the researcher prefers to perform it in collective questionnaire as compared to the online version. Majority of the academicians in the faculty are helpful and collaborative enough to lend a hand in the survey distribution phase. The undergraduate student's weak experiences of using email and online questionnaire was another reason for the researcher to choose the collective method.

The data collection step was carried out from August to September 2018. A total number of 208 undergraduate students had participated in this study. Thirty of them were chosen for the pilot study. The rest of them were used for the actual study, which were 178. Out of the number of questionnaires distributed, 162 were returned to the researcher. After checking the questionnaires responses, 148 of the 162 of the returned were valid, completed and used for the analysis, which is a good feedback. The number of questionnaires that are valid completed and returned are more than $60 \%$ of the total questionnaires distributed. This is considered a good number for the data analysis and report [3]. Table III shows the response rates and percentages on survey questionnaire distributed.

When the questionnaires were collected, sorted and checked, the data was entered to IBM SPSS 23 statistical package for analysis.

TABLE III. RESPONSE RATES AND PERCENTAGES ON QUeSTIONNAIRE

\begin{tabular}{|l|l|l|l|}
\hline Description & Distributed in actual study & Returned & Valid \\
\hline $\begin{array}{l}\text { No. of } \\
\text { questionnaire }\end{array}$ & 178 & 162 & 148 \\
\hline Percentage & $100 \%$ & $91 \%$ & $83 \%$ \\
\hline
\end{tabular}

\section{RESULTS AND DISCUSSIONS}

\section{A. Demographic Information}

This first section of the survey questionnaire is on respondent demographic information. The demographic information involved department, sex, age, mobile technologies own, frequency of mobile technologies usage and hours spend on the device involved. A total number of 148 respondents involved in this survey. Information is presented in Table IV.

Table IV indicates from 148 respondents, majority of them are from IT department (50.7), 49.3\% are from CS department. Meanwhile, majority of the respondents are male with $62.2 \%$ as compared to female with $37.8 \%$. The number of male respondents is more than females because in most of Arab countries women' right is still not fulfilled specially in education. Therefore, the number of females in HE institutions still smaller if compared to males. Majority of them with 80.4 $\%$ age from 20-24 years old, followed by 15-19 years old
(13.5\%), and 25-30 with 6.1\%. Most of the respondent age from 20-24 years old is due to the education systems, which force students to start studying at the age of seven and then twelve years for primary and secondary. Following that, students are forced to have one-year vacation. When calculating, it is discovered that early twenties is the age for majority of students in the first year unless there are special cases. Regarding the mobile technologies ownership, majority of them own a laptop (81.8\%), while the rest does not own a laptop $(18.2 \%)$.

Meanwhile, all of the respondents own a mobile or smart phone. A total number of $85.8 \%$ of the respondent own a tablet, while only $14.2 \%$ among them does not own a tablet. Based on the output on mobile technologies usage, most of the respondents are using the laptop for 2-5 years (33.8\%), followed by months -1 years $(23.6 \%)$, never $(23.0 \%)$ and over 5 years $(19.6 \%)$. Majority of them are using the smartphone more than 5 years $(49.3 \%)$, followed by $2-5$ years' usage $(38.5 \%)$, and the least is month-1 year (12.2\%). Surprisingly, majority number of the respondent never uses a tablet. This is due to the fragility of tablets and quickly damaged. While another $8.8 \%$ had use them over 5 years, followed by $2-5$ years $(7.7 \%)$ and the least is months-1 year $(2.7 \%)$.

The results on daily usage of each devices reveals that the respondents commonly spend approximately 1-5 hours $(64.9 \%)$ on the laptop usage, whereas only few of them spend more than 10 hours on the laptop usage. The smart phone is commonly utilized daily with approximately 1-5 hours (45.3\%). Lastly, only $9.5 \%$ of the respondents spend they daily time on tablet. This is because majority number of the respondents does not own a tablet.

\section{B. Overall Utilization of Mobile Technologies among Undergraduates}

This section is design to identify the level of mobile technologies utilization based on user's frequency of using mobile technologies. In this section the question "What is the level of utilization among first year undergraduate students when using mobile technologies?" will be answered in this part of the results. To answer this question, the respondents were asked to indicate their level of frequency on each purpose of mobile technologies utilization which was measured by the five Likert scale; (1) never, (2) Rarely (once or twice), (3) Sometimes ( $2-3$ times a week), (4) Often (4-6 times a week) and to the most frequent use (5) almost every day. The results presented involved 148 respondents respectively. The results of all dimensions in the dependent variables will be stated like in the Table IV.

As mentioned earlier, one of the objectives of this study is to study on the level of mobile technologies utilization among CS \& IT undergraduates' students in general. Therefore, based on Table $\mathrm{V}$, the output had confirmed that out of six factors of mobile technologies utilization purposes, majority of the undergraduates' students frequently used the mobile technologies by means of communication $(\mathrm{M}=4.6, \mathrm{SD}=$ 2.62). Following that, basic operation purposes $(\mathrm{M}=4.0, \mathrm{SD}=$ 4.02) and information seeking $(\mathrm{M}=4.0, \mathrm{SD}=3.50)$ are equally and highly utilized by $\mathrm{HE}$ students. Creativity and innovation with $(\mathrm{M}=3.56, \mathrm{SD}=2.46)$ is in the third rank. 
Lastly, Digital citizenship with $(\mathrm{M}=3.0, \mathrm{SD}=4.88)$ and collaboration purpose $(\mathrm{M}=3.0, \mathrm{SD}=2.39)$ are as noticed the least equally utilized among the students.

TABLE IV. RESPONDENT'S DEMOGRAPHIC

\begin{tabular}{|c|c|c|c|}
\hline Variables & Category & Frequency & Percentage \\
\hline Department & $\begin{array}{l}\text { CS } \\
\text { IT }\end{array}$ & $\begin{array}{l}73 \\
75\end{array}$ & $\begin{array}{l}49.3 \\
50.7\end{array}$ \\
\hline Sex & $\begin{array}{l}\text { Male } \\
\text { Female }\end{array}$ & $\begin{array}{l}92 \\
56\end{array}$ & $\begin{array}{l}62.2 \\
37.8\end{array}$ \\
\hline Age & $\begin{array}{l}15-19 \\
20-24 \\
25-30\end{array}$ & $\begin{array}{l}20 \\
119 \\
9\end{array}$ & $\begin{array}{l}13.5 \\
80.4 \\
6.1\end{array}$ \\
\hline Own laptop & $\begin{array}{l}\text { Yes } \\
\text { No }\end{array}$ & $\begin{array}{l}121 \\
21\end{array}$ & $\begin{array}{l}81.8 \\
18.2\end{array}$ \\
\hline Own mobile & $\begin{array}{l}\text { Yes } \\
\text { No }\end{array}$ & $\begin{array}{l}148 \\
-\end{array}$ & $\begin{array}{l}100 \\
-\end{array}$ \\
\hline Own tablet & $\begin{array}{l}\text { Yes } \\
\text { No }\end{array}$ & $\begin{array}{l}21 \\
127\end{array}$ & $\begin{array}{l}14.2 \\
85.8\end{array}$ \\
\hline Period of using laptop & $\begin{array}{l}\text { Never } \\
\text { months - } 1 \text { year } \\
2 \text { years - } 5 \text { years } \\
\text { over } 5 \text { years }\end{array}$ & $\begin{array}{l}34 \\
35 \\
50 \\
29\end{array}$ & $\begin{array}{l}23.0 \\
23.6 \\
33.8 \\
19.6 \\
\end{array}$ \\
\hline Period of using smartphone & $\begin{array}{l}\text { Never } \\
\text { months - } 1 \text { year } \\
2 \text { years - } 5 \text { years } \\
\text { over } 5 \text { years }\end{array}$ & $\begin{array}{l}- \\
18 \\
57 \\
73\end{array}$ & $\begin{array}{l}- \\
12.2 \\
38.5 \\
49.3 \\
\end{array}$ \\
\hline Period of using tablet & $\begin{array}{l}\text { Never } \\
\text { months - } 1 \text { year } \\
2 \text { years - } 5 \text { years } \\
\text { over } 5 \text { years } \\
\end{array}$ & $\begin{array}{l}124 \\
4 \\
7 \\
13 \\
\end{array}$ & $\begin{array}{l}83.8 \\
2.7 \\
7.7 \\
8.8 \\
\end{array}$ \\
\hline $\begin{array}{l}\text { Period of using laptop } \\
\text { (daily) }\end{array}$ & $\begin{array}{l}\text { Never } \\
1 \text { hour }-5 \text { hours } \\
6 \text { hours - } 10 \\
\text { hours } \\
\text { More than } 10 \\
\text { hours }\end{array}$ & $\begin{array}{l}32 \\
96 \\
12 \\
8\end{array}$ & $\begin{array}{l}21.6 \\
64.9 \\
8.1 \\
5.4\end{array}$ \\
\hline $\begin{array}{l}\text { Period of using smartphone } \\
\text { (daily) }\end{array}$ & $\begin{array}{l}\text { Never } \\
1 \text { hour }-5 \text { hours } \\
6 \text { hours - } 10 \\
\text { hours } \\
\text { More than } 10 \\
\text { hours }\end{array}$ & $\begin{array}{l}- \\
67 \\
44 \\
37\end{array}$ & $\begin{array}{l}- \\
45.3 \\
29.7 \\
25.0\end{array}$ \\
\hline $\begin{array}{l}\text { Period of using tablet } \\
\text { (daily) }\end{array}$ & $\begin{array}{l}\text { Never } \\
1 \text { hour }-5 \text { hours } \\
6 \text { hours - } 10 \\
\text { hours } \\
\text { More than } 10 \\
\text { hours }\end{array}$ & $\begin{array}{l}131 \\
14 \\
3 \\
-\end{array}$ & $\begin{array}{l}88.5 \\
9.5 \\
2.0 \\
-\end{array}$ \\
\hline
\end{tabular}

TABLE V. THE LEVEl of MoBiLE TeChNOLOGIES UtilisATION AMONG CS AND IT UNDERGRADUATE STUDENTS

\begin{tabular}{|l|l|l|l|l|}
\hline Items & N & Mean & SD & Rank \\
\hline Communication & 148 & 4.6 & 2.62 & 1 \\
\hline Basic operation Purposes & 148 & 4.0 & 4.02 & 2 \\
\hline Information Seeking & 148 & 4.0 & 3.50 & 2 \\
\hline Creativity and Innovation & 148 & 3.56 & 2.46 & 3 \\
\hline Digital Citizenship & 148 & 3.0 & 4.88 & 4 \\
\hline Collaboration & 148 & 3.0 & 2.39 & 4 \\
\hline
\end{tabular}

\section{Overall Competency of Mobile Technologies among Undergraduates}

This section is designed to identify the level of mobile technologies competency based on user's skilfulness of using mobile technologies. In this section, the question "What is the level of competency among first year undergraduate students when using mobile technologies?" will be answered in this part of the results. To answer this question, the respondents were asked to indicate their level of skilfulness on each purpose when using these devices which was measured by the five Likert scale: (1) No skills in this area, (2) Limited skills in this area, (3) enough Skills: Need refinements, (4) Skilful (5) Very Skilful. The results presented involved 148 respondents respectively.

The results in Table VI clearly displays that the most prominent competency level among the students is as expected basic operation tools $(\mathrm{M}=3.9, \mathrm{SD}=3.49)$, followed by information seeking tools $(\mathrm{M}=3.8, \mathrm{SD}=3.10)$. Thirdly, $\mathrm{HE}$ students are competent in communication purposes $(\mathrm{M}=3.7$, $\mathrm{SD}=3.78$ ). Meanwhile, creativity and innovation tools is unexpectedly the next mastered skill among the students (M $=3.4, \mathrm{SD}=2.52)$. The HE students are least skilled on digital citizenship $(\mathrm{M}=3.0, \mathrm{SD}=4.40)$ and collaboration $(\mathrm{M}=2.9$, $\mathrm{SD}=2.07$ ).

Table VII demonstrates the results on the overall results of utilization and competency of mobile technologies in the learning field conducted among the undergraduates' students. Based on the above table, it can be clearly seen that the results of overall utilization of mobile learning is $(\mathrm{M}=3.78, \mathrm{SD}$ $=12.1)$. Meanwhile, the overall competency level is $(\mathrm{M}=3.53$, $\mathrm{SD}=13.5)$. Hence, the results had indicated that CS \& IT undergraduates in Hadhramout University are highly utilizing the mobile technologies in their hands. Moreover, it is indicating that these students are so competent in using these devices for the six purposes.

TABLE VI. RESUlTS ON OVERALl COMPETENCY LEVEL OF MOBILE TECHNOLOGIES

\begin{tabular}{|l|l|l|l|l|}
\hline Items & $\mathrm{N}$ & Mean & $\mathrm{SD}$ & Rank \\
\hline Basic operation Tools & 148 & 3.9 & 3.49 & 1 \\
\hline Information Seeking Tools & 148 & 3.8 & 3.10 & 2 \\
\hline Communication Purposes & 148 & 3.7 & 3.78 & 3 \\
\hline Creativity and Innovation Tools & 148 & 3.4 & 2.52 & 4 \\
\hline Digital Citizenship Tools & 148 & 3.0 & 4.40 & 5 \\
\hline Collaboration Purposes & 148 & 2.9 & 2.07 & 6 \\
\hline
\end{tabular}

TABLE VII. OVERALL; MEAN SCORE AND STANDARD DEVIATION FOR MOBILE LEARNING UTILIZATION AND COMPETENCY LEVEL

\begin{tabular}{|l|l|l|}
\hline Dimension & N & Mean \\
\hline Overall utilization & 148 & 3.78 \\
\hline Overall competency & 148 & 3.53 \\
\hline
\end{tabular}




\section{Individual Level of Utilization and Competency for all Dimensions among Undergraduates}

Now a detailed description about which of the statements in the dimensions are higher will be displayed in the following tables. In this section the question "What is the level of basic operation, communication and collaboration, information Seeking, digital citizenship and creativity and innovation skills in mobile technologies competency and utilization separately?" will be answered. First, detailed results for all dimensions in utilization of mobile technologies will be provided. Second, the results will detail data about all dimensions in competency of mobile technologies.

1) All dimensions in utilization of mobile technologies: Table 8 above demonstrates the results on mobile technologies for basic operation purposes. According to previous literature review, seven significant dimensions identified were included under mobile technologies for basic operation purposes. These dimensions are: i) sharing files and documents, ii) setting time and place for an event, iii) capturing pictures, iv) recording videos, v) installing applications, vi) organizing files into folders and vii) opening several programs simultaneously. Based on the compare of mean results, it can be clearly seen that the most highly utilize mobile technology under this factor which rank as the first is operating several program simultaneously ( $\mathrm{M}=4.34, \mathrm{SD}=.676)$, followed by organizing files into folders $(M=4.09, S D=.755)$. Meanwhile, the third highest utilization ranked is recording videos $(\mathrm{M}=4.07, \mathrm{SD}=$ $.809)$, followed by (setting time and place for an event ( $\mathrm{M}=$ $4.05, \mathrm{SD}=.875)$, installing application $(\mathrm{M}=4.01, \mathrm{SD}=.861)$, capturing pictures $(\mathrm{M}=3.90, \mathrm{SD}=.855)$ and the least utilized among the undergraduate's students of this faculty is sharing files and documents $(\mathrm{M}=3.08, \mathrm{SD}=.849)$.

In this subsection, the respondent was asked to indicate their level of frequency of communication with three groups of people that are friends, lecturer, and family members with similar scale of 1 to 5 as previous aforementioned section. Each table below demonstrates the results generated on the level of utilization of mobile technologies using SPSS.

Table IX displays the results on communication purposes using mobile technology among the respondent with their friends. Three significant communication medium used as dimension in this subsection are: i) voice, ii) video and iii) email. Based on the above table, the results proved that the most highly utilize mobile technologies under this factor is using email $(\mathrm{M}=4.61, \mathrm{SD}=.504)$, followed by video $(\mathrm{M}=$ $4.57, \mathrm{SD}=.510)$ and lastly voice $(\mathrm{M}=4.54, \mathrm{SD}=.539)$. Voice is the most preferred communication medium, because it is more expressive especially when they are very busy. Meanwhile, email is the least preferred communication medium with their friends, because most of what they are sharing is talks and chats. Moreover, they do have the same way of thinking that emails are meant for official matters only.

TABLE VIII. MobILE TECHNOLOGIES FOR BASIC OPERATION PURPOSES RESUltS

\begin{tabular}{|l|l|l|l|l|l|l|}
\hline Item & N & Min & Max & Mean & SD \\
\hline Opening several programs simultaneously & 148 & 3 & 5 & 4.34 & .676 \\
\hline Organizing files into folders & 148 & 3 & 5 & 4.09 & .755 \\
\hline Recording videos & 148 & 2 & 5 & 4.07 & 2 \\
\hline Setting time and place for an event & 148 & 2 & 5 & 4.05 & .809 \\
\hline Installing applications & 148 & 1 & 5 & 4.01 & 3 \\
\hline Capturing pictures & 148 & 2 & 5 & 3.90 & .861 \\
\hline Sharing files and documents & 148 & 1 & 5 & 3.86 & 5 \\
\hline
\end{tabular}

TABle IX. Mobile TeChNologies For Communication Purposes Results (FriENDS)

\begin{tabular}{|c|c|c|c|c|c|c|}
\hline Item & $\mathrm{N}$ & Min & Max & Mean & SD & Rank \\
\hline UTICF (Email) & 148 & 3 & 5 & 4.61 & .504 & 1 \\
\hline UTIF(Video) & 148 & 3 & 5 & 4.57 & .510 & 2 \\
\hline UTIF (Voice) & 148 & 3 & 5 & 4.54 & .539 & 3 \\
\hline
\end{tabular}

TABle X. Mobile Technologies for Communication Purposes Results (LeCturer)

\begin{tabular}{|l|l|l|l|l|l|l|}
\hline Item & $\mathrm{N}$ & Min & Max & Mean & SD & Rank \\
\hline UTICL (video) & 148 & 3 & 5 & 4.65 & .507 & 1 \\
\hline UTICL (email) & 148 & 3 & 5 & 4.62 & .514 & 2 \\
\hline UTIL (voice) & 148 & 3 & 5 & 4.59 & .521 \\
\hline
\end{tabular}


Table $\mathrm{X}$ indicates the results on communication purposes using mobile technology among the respondent with their lecturers. Three significant communication medium used as dimension in this subsection are: i) voice, ii) video and iii) email. Based on the above table, the results demonstrate that the most highly used communication medium that students used to communicate with the lecturers is video $(\mathrm{M}=$ $4.65, \mathrm{SD}=.507)$, followed by email $(\mathrm{M}=4.62, \mathrm{SD}=.514)$ and lastly voice $(\mathrm{M}=4.59, \mathrm{SD}=.521)$. As compared to previous results of which they prefer to communicate with their friends using email, majority of the students prefers to communicate using video with their lecturer. This is due to the mode of teaching and studying. Some of the teachers attempt to let the students experience different modes of delivering information. Therefore, they were videotaping their lectures. Furthermore, students sometimes are asked to video tape themselves when doing some of their assignments. Moreover, voice is the least preferred communication medium is because it not much required by their lecturer when they are asking them to do an assignment. Note that the communication is not face-to-face type rather than it is recorded videos.

Table XI shows the results on communication purposes using mobile technology among the respondent with their family. Based on the above table, the results indicate that the most highly used communication medium that undergraduates used to communicate with their family members is using voice $(\mathrm{M}=4.60, \mathrm{SD}=.518)$, followed by video $(\mathrm{M}=4.59, \mathrm{SD}=$ $.520)$ and lastly email $(\mathrm{M}=4.59, \mathrm{SD}=.521)$. The results clearly stated that respondents prefer to communicate with their family using voice as compared to video and email. Voice is the most preferable communication medium because videos are difficult to be used if compared. The videos would have been the most preferred unless the bandwidth is very terrible in the countryside (most of the students are either form KSA or countryside). They feel that text is not fulfilling what they want to say and videos are hard to use. Then, it is only through the voice that they, with little difficulty, can send voice mails rather than calling.

Table XII demonstrates the results on the level of utilization of mobile technologies for collaboration purposes. The results indicate that the most frequently used mobile technologies for collaboration is delivering a presentation via a videoconference $(\mathrm{M}=3.08, \mathrm{SD}=.973)$, followed by attending a webinar $(\mathrm{M}=2.97, \mathrm{SD}=.979)$, and the least use is sharing ideas via other people's blogs, social forum, social networking sites' walls etc. $(\mathrm{M}=2.82, \mathrm{SD}=.822)$. The students frequently use to deliver a presentation via a videoconference as compared to two other factors is mainly due to the well -equipped labs. Due to the university, powerful internet bandwidth, which is wireless, lecturers, experiences the video conferences with their friends from other countries. It is one of the new styles of teaching in this outstanding college. That happens only inside the college.

Table XIII displays the output on the level of utilization of mobile technologies for information seeking purposes. The results prove that the most frequently used mobile technologies under the information seeking categories factor is to get latest information from subscribing portal/ website (M $=4.14, \mathrm{SD}=.753$ ). The next result is the one of getting latest information by signing up for newsletter of portals and websites $(\mathrm{M}=4.07, \mathrm{SD}=.739)$. After that is finding latest information on subject / topic by browsing with $(\mathrm{M}=4.03$, SD $=.884)$. Then updating list of portals and websites in bookmark $(\mathrm{M}=3.92, \mathrm{SD}=.796)$ is following. Bookmarking portals and website related to the field $(\mathrm{M}=3.89, \mathrm{SD}=.905)$ is the next. After that, browsing to find references $(\mathrm{M}=3.84, \mathrm{SD}$ $=.825)$ is the next. The least utilized information using mobile technologies among the students is downloading learning materials from portals and websites $(\mathrm{M}=3.80, \mathrm{SD}=.873)$. The students frequently utilized the mobile technologies to get latest information from subscribing portal/ website mainly because there is always new information in computer science and information technology field offered in portals and websites guaranteed by the lecturers. Moreover, lecturers in this college keep always asking them to collect info from the authorized portals and websites to keep them up to date.

Table XIV presents the result on the level of utilization of mobile technologies for digital citizenship purposes. The results have proven that the most frequently used mobile technologies under this factor is to using other people' works lawfully $(\mathrm{M}=3.49, \mathrm{SD}=.951)$. It is followed by learning and prevent on cyber bullying $(\mathrm{M}=3.22, \mathrm{SD}=1.07)$ and expressing myself through digital media $(\mathrm{M}=3.16, \mathrm{SD}=$ .931). After that, it is the item "creating strong passwords to protect my private information $(\mathrm{M}=3.08, \mathrm{SD}=.944)$ " and "protecting my digital works through the copyright $(\mathrm{M}=2.96$, $\mathrm{SD}=.790)$ ". Next, is the items "finding out required information $(\mathrm{M}=2.86, \mathrm{SD}=.901)$ and "evaluating information $(\mathrm{M}=2.84, \mathrm{SD}=.886)$ ". The least frequently used are "identifying valuable information $(\mathrm{M}=2.81, \mathrm{SD}=.884)$ " and "using information effectively $(\mathrm{M}=2.71, \mathrm{SD}=.859)$ ". Using other people's work lawfully is the most preferable is due to the continuous warnings given to them by their lecturer. When the researcher asked the lecturers about this issue, their answer was "we give them stories happened in the countries we studied in to draw the awareness to this issue".

TABLE XI. MoBILE TECHNOLOGIES FOR COMMUNICATION PURPOSES RESULTS (FAMILY)

\begin{tabular}{|l|l|l|l|l|l|l|}
\hline Item & $\mathrm{N}$ & Min & Max & Mean & SD & Rank \\
\hline UTICFA(voice) & 148 & 3 & 5 & 4.60 & .518 & 1 \\
\hline UTICFA(video) & 148 & 3 & 5 & 4.59 & .520 & 2 \\
\hline UTICFA(email) & 148 & 3 & 5 & 4.59 & .521 & 3 \\
\hline
\end{tabular}

TABLE XII. Mobile Technologies for Collaboration Purposes

\begin{tabular}{|l|l|l|l|l|l|l|}
\hline Item & $\mathrm{N}$ & Min & Max & Mean & SD & Rank \\
\hline $\begin{array}{l}\text { Delivering a } \\
\text { presentation via a } \\
\text { video Conference }\end{array}$ & 148 & 1 & 5 & 3.08 & .973 & 1 \\
\hline $\begin{array}{l}\text { Attending a } \\
\text { webinar }\end{array}$ & 148 & 1 & 5 & 2.97 & .979 & 2 \\
\hline $\begin{array}{l}\text { Sharing ideas via } \\
\text { other people's } \\
\text { blogs, social } \\
\text { forum, Social } \\
\text { Networking Sites' } \\
\text { walls etc }\end{array}$ & 148 & 1 & 5 & 2.82 & .822 & 3 \\
\hline
\end{tabular}


TABLE XIII. MoBILE TeChNOLOGIES FOR INFORMATION SEEKING PURPOSES

\begin{tabular}{|c|c|c|c|c|c|c|}
\hline Item & $\mathrm{N}$ & Min & $\operatorname{Max}$ & Mean & SD & Rank \\
\hline Get latest information from subscribing portal/ website & 148 & 2 & 5 & 4.14 & .753 & 1 \\
\hline Get latest information by signing up for newsletter of portals and websites & 148 & 2 & 5 & 4.07 & .739 & 2 \\
\hline Finding latest information on subject / topic by browsing. & 148 & 2 & 5 & 4.03 & .884 & 3 \\
\hline Updating list of portals and websites in bookmark & 148 & 1 & 5 & 3.92 & .796 & 4 \\
\hline Bookmarking portals and website related to the field & 148 & 1 & 5 & 3.89 & .905 & 5 \\
\hline Browsing to find references & 148 & 1 & 5 & 3.84 & .825 & 6 \\
\hline Downloading learning materials from portals and websites & 148 & 1 & 5 & 3.80 & .873 & 7 \\
\hline
\end{tabular}

TABLE XIV. Mobile TeChNOLOGIES FOR Digital Citizenship PURPoSeS

\begin{tabular}{|c|c|c|c|c|c|c|}
\hline Items & $\mathrm{N}$ & Min & Max & Mean & SD & Rank \\
\hline Using other people' works lawfully & 148 & 2 & 5 & 3.49 & .951 & 1 \\
\hline Learning what to do if involved in cyberbullying \& how to overcome & 148 & 1 & 5 & 3.22 & 1.07 & 2 \\
\hline Expressing myself through digital media & 148 & 1 & 5 & 3.16 & .931 & 3 \\
\hline Creating strong passwords to protect my private information & 148 & 1 & 5 & 3.08 & .944 & 4 \\
\hline Protecting my digital works through the copyright & 148 & 1 & 5 & 2.96 & .790 & 5 \\
\hline Finding out required information & 148 & 1 & 5 & 2.86 & .901 & 6 \\
\hline Evaluating information & 148 & 1 & 5 & 2.84 & .886 & 7 \\
\hline Identifying valuable information & 148 & 1 & 5 & 2.81 & .844 & 8 \\
\hline Using information effectively & 148 & 1 & 5 & 2.71 & .859 & 9 \\
\hline
\end{tabular}

TABLE XV. MobILE TeChNOLOGIES For CREATIVITy AND INNOVATION PURPoSES

\begin{tabular}{|l|l|l|l|l|l|l|}
\hline Items & N & Min & Max & Mean & SD & Rank \\
\hline Uploading work & 148 & 1 & 5 & 3.61 & .779 & 1 \\
\hline Creating an innovation/product & 148 & 2 & 5 & 3.59 & .832 & 2 \\
\hline Producing work & 148 & 2 & 5 & 3.57 & .661 & 3 \\
\hline Performing advanced searches & 148 & 2 & 5 & 3.51 & .705 & 4 \\
\hline constructing an original work & 148 & 2 & 5 & 3.50 & .655 & 5 \\
\hline
\end{tabular}

Referring to Table XV, the results on mobile technologies for creativity and innovation purposes shows that uploading work is the most frequently perform under this factor $(\mathrm{M}$ $=3.61, \mathrm{SD}=.779)$. Meanwhile, the second highest preferred is by creating an innovation/product $(\mathrm{M}=3.59, \mathrm{SD}=.832)$, followed by producing work $(\mathrm{M}=3.57, \mathrm{SD}=.661)$, performing advance searches $(\mathrm{M}=3.51, \mathrm{SD}=705)$, and lastly the students choose to utilized the mobile technologies by constructing an original work $(\mathrm{M}=3.50, \mathrm{SD}=.655)$. The students highly utilized the mobile technologies by uploading their works due to the assignment that they have to do and then upload to their face book group to discuss it with their peers.

Finally, it could be concluded that_communication is the most highly utilized by the students is due to certain reasons. These students are far from their families; therefore, they need to contact their families from time to time. More importantly, these students are given assignments to answer in a due time. For this purpose, students may contact their lecturers to have a clear picture about the assignment or they may ask their classmates instead. This notion is supported by the study conducted by Murphy (2011). In this study, it is revealed that students are very energetically using technologies available for communication purposes to facilitate their learning process through interactions.

2) All dimensions in competency of mobile technologies: Table XVI shows the results of competency of mobile technologies as basic operation tools. The above table indicates that the most highly rated skill is opening several programs simultaneously $(\mathrm{M}=4.20, \mathrm{SD}=.670)$, followed by organizing files into folders $(\mathrm{M}=3.97, \mathrm{SD}=.713)$, recording video $(M=3.96, S D=.737)$, setting time and place for an event $(\mathrm{M}=3.95, \mathrm{SD}=.772)$, sharing files and documents $(\mathrm{M}=3.78$, $\mathrm{SD}=.787)$, installing applications $(\mathrm{M}=3.78, \mathrm{SD}=.655)$. The least competency level in this category is capturing pictures $(\mathrm{M}=3.76$, $\mathrm{SD}=.732)$. Opening several programs simultaneously is the most prominent factor.

Table XVII displays the results on communication purposes using mobile technology among the respondent with 
their friends. Three significant communication medium used as dimension in this subsection are: i) voice, ii) video and iii) email. Based on the above table, the results proved that the most skilful mobile technology among the students while communicating with their friends is email $(\mathrm{M}=4.11, \mathrm{SD}=$ $.675)$, followed by voice and video with $(\mathrm{M}=4.10, \mathrm{SD}=$ $.726)$ and $(\mathrm{M}=4.09, \mathrm{SD}=.699)$. Meanwhile, Table XVIII below present the results on competency of communication with their lecturers.

Based on Table XVIII, the output demonstrates that communicating with video is the highest competency level (M $=4.18, \mathrm{SD}=.716$ ), followed by communicating using email $(\mathrm{M}=4.13, \mathrm{SD}=.663)$, and communicating using voice $(\mathrm{M}=$ $3.98, \mathrm{SD}=.665)$. The results for competency level with their family are presented in Table XVIII.

Table XIX displays the output of competency level of mobile technologies of communication factor. The most highly rank is communicating using email $(\mathrm{M}=4.14, \mathrm{SD}=$ $.650)$, followed by communicating using voice $(\mathrm{M}=4.12$, SD $=.737)$ and communicating using video $(\mathrm{M}=4.05, \mathrm{SD}=$ .668).

Table XX indicates the overall competency level of mobile technologies. The outcomes demonstrate that the competency with family is the highest $(\mathrm{M}=12.3, \mathrm{SD}=1.56)$, followed by friends $(\mathrm{M}=8.76, \mathrm{SD}=2.07)$, and lecturer $(\mathrm{M}=2.96, \mathrm{SD}=$ .798). Therefore, based on the results it is proven that students are more competent in the use of mobile technologies for communicating their families due to the distance between them and their families. It could be also speculated that they still have the influence of the surrounding environment that are skilful in the use of mobile technologies as a tool for social communication rather educational or study communication.

TABLE XVI. COMPetency of Mobile TeChNologies AS BASIC OPERATION TOOLS

\begin{tabular}{|l|l|l|l|l|l|l|}
\hline Items & $\mathrm{N}$ & Min & Max & Mean & SD & Rank \\
\hline $\begin{array}{l}\text { Opening several } \\
\text { programs } \\
\text { simultaneously }\end{array}$ & 148 & 3 & 5 & 4.20 & .670 & 1 \\
\hline $\begin{array}{l}\text { Organizing files } \\
\text { into folders }\end{array}$ & 148 & 2 & 5 & 3.97 & .713 & 2 \\
\hline Recording videos & 148 & 2 & 5 & 3.96 & .737 & 3 \\
\hline $\begin{array}{l}\text { Setting time and } \\
\text { place for an event }\end{array}$ & 148 & 2 & 5 & 3.95 & .772 & 4 \\
\hline $\begin{array}{l}\text { Sharing files and } \\
\text { documents. }\end{array}$ & 148 & 2 & 5 & 3.78 & .787 & 5 \\
\hline $\begin{array}{l}\text { Installing } \\
\text { applications }\end{array}$ & 148 & 2 & 5 & 3.78 & .655 & 6 \\
\hline Capturing pictures & 148 & 2 & 5 & 3.76 & .732 & 7 \\
\hline
\end{tabular}

TABLE XVII. COMPETENCY OF MOBILE TECHNOLOGIES FOR COMMUNICATION PURPOSES (FRIENDS)

\begin{tabular}{|l|l|l|l|l|l|l|}
\hline Item & $\mathrm{N}$ & Min & Max & Mean & SD & Rank \\
\hline Communicating using email & 148 & 2 & 5 & 4.11 & .675 & 1 \\
\hline Communicating using voice & 148 & 2 & 5 & 4.10 & .726 & 2 \\
\hline Communicating using video & 148 & 2 & 5 & 4.09 & .699 & 3 \\
\hline
\end{tabular}

TABLE XVIII.COMPETENCY OF MOBILE TECHNOLOGIES FOR COMMUNICATION PURPOSES (LECTURERS)

\begin{tabular}{|l|l|l|l|l|l|l|}
\hline Items & $\mathrm{N}$ & Min & Max & Mean & SD & Rank \\
\hline Communicating using video & 148 & 2 & 5 & 4.18 & .716 & 1 \\
\hline Communicating using email & 148 & 2 & 5 & 4.13 & .663 & 2 \\
\hline Communicating using voice & 148 & 2 & 5 & 3.98 & .665 & 3 \\
\hline
\end{tabular}

TABLE XIX. COMPETENCY OF MOBILE TECHNOLOGIES FOR COMMUNICATION PURPOSES (FAMILY MEMBERS)

\begin{tabular}{|l|l|l|l|l|l|l|}
\hline Items & $\mathrm{N}$ & Min & Max & Mean & SD & Rank \\
\hline Communicating using email & 148 & 3 & 5 & 4.14 & .650 & 1 \\
\hline Communicating using voice & 148 & 2 & 5 & 4.12 & .737 & 2 \\
\hline Communicating using video & 148 & 2 & 5 & 4.05 & .668 & 3 \\
\hline
\end{tabular}

TABLE XX. RESULTS ON COMPETENCY OF COMMUNICATION WITH ALL

\begin{tabular}{|l|l|l|l|l|}
\hline Items & $\mathrm{N}$ & Mean & SD & Rank \\
\hline Family & 148 & 12.3 & 1.56 & 1 \\
\hline Friends & 148 & 8.76 & 2.07 & 2 \\
\hline Lecturer & 148 & 2.96 & .798 & 3 \\
\hline
\end{tabular}

Table XXI presents the output of competency level of mobile technologies for collaboration purposes. Delivering presentation via video conference $(\mathrm{M}=3.04, \mathrm{SD}=.880)$ is the highest competency level among the students, followed by attending a webinar $(\mathrm{M}=2.91, \mathrm{SD}=.819)$ and sharing ideas via social media platform $(\mathrm{M}=2.81, \mathrm{SD}=.732)$.

In Table XXII, it is stated above out of seven dimension tested, get the latest information by signing for newsletter (M $=4.00 \mathrm{SD}=.690$ ) is the most prominent skills owned by the students. This is followed by acquiring the latest information via website $(\mathrm{M}=3.93 \mathrm{SD}=.650)$, findings the current information by browsing $(\mathrm{M}=3.84 \mathrm{SD}=.774)$, updating list of portal $(\mathrm{M}=3.77 \mathrm{SD}=.681)$. Meanwhile, bookmarks portal and website related to the subject expertise is the next rated skills ( $\mathrm{M}=3.76, \mathrm{SD}=.846$ ), followed by surfing the net to find references $(\mathrm{M}=3.74, \mathrm{SD}=.741)$ and lastly downloading from websites the learning materials $(\mathrm{M}=3.68, \mathrm{SD}=.700)$.

Table XXIII presents the results on competency of digital citizenship among the undergraduates' students. The most highly rated skill is using other people's work lawfully (M $=3.36, \mathrm{SD}=.817$ ). This is followed by learning knowledge related to cyber bullying $(\mathrm{M}=3.16, \mathrm{SD}=.896)$, expressing self through media $(\mathrm{M}=3.10, \mathrm{SD}=.831)$, creating password for privacy purposes $(\mathrm{M}=3.08, \mathrm{SD}=.829)$, creating copyright of work $(\mathrm{M}=2.98, \mathrm{SD}=.742)$. Meanwhile, finding information is the next competency level rated with $(\mathrm{M}=2.94$, $\mathrm{SD}=.784)$, evaluating information $(\mathrm{M}=2.91, \mathrm{SD}=.808)$, identifying valuable information $(\mathrm{M}=2.86, \mathrm{SD}=.774)$. The least ranked competency skills among the students is using the information effectively $(\mathrm{M}=2.79, \mathrm{SD}=.731)$.

Table XXIV demonstrates the findings on mobile technology competency of creativity and innovation tools. The most advanced skills owned by the undergraduates' students is uploading work $(\mathrm{M}=3.48, \mathrm{SD}=.778)$. The second skill 
mastered is creating an innovation /products using mobile technologies $(\mathrm{M}=3.47, \mathrm{SD}=.812)$. Next competency ability is producing work $(\mathrm{M}=3.41, \mathrm{SD}=.649)$, followed by performing advanced searches $(\mathrm{M}=3.40, \mathrm{SD}=.687)$ and constructing an original work $(\mathrm{M}=3.35, \mathrm{SD}=.648)$.

TABLE XXI. COMPETENCY OF MOBILE TECHNOLOgIES FOR COLLABORATION PURPOSES

\begin{tabular}{|c|c|c|c|c|c|c|}
\hline Items & $\mathrm{N}$ & Min & $\operatorname{Max}$ & Mean & SD & Rank \\
\hline Delivering a presentation via a video conference & 148 & 1 & 5 & 3.04 & .880 & 1 \\
\hline Attending a webinar & 148 & 1 & 5 & 2.91 & .819 & 2 \\
\hline $\begin{array}{l}\text { Sharing ideas via other people's blogs, social forum, Social Networking } \\
\text { Sites' walls etc }\end{array}$ & 148 & 2 & 4 & 2.81 & .732 & 3 \\
\hline
\end{tabular}

TABLE XXII. COMPETENCY OF MOBILE TECHNOLOGIES FOR INFORMATION SEEKING TOOLS

\begin{tabular}{|c|c|c|c|c|c|c|}
\hline Items & $\mathrm{N}$ & Min & $\operatorname{Max}$ & Mean & $\mathrm{SD}$ & Rank \\
\hline Get latest information by signing up for newsletter of portals and websites & 148 & 2 & 5 & 4.00 & .690 & 1 \\
\hline Get latest information from subscribing portal/ website & 148 & 2 & 5 & 3.93 & .650 & 2 \\
\hline Finding latest information on subject / topic by browsing. & 148 & 2 & 5 & 3.84 & .774 & 3 \\
\hline Updating list of portals and websites in bookmark & 148 & 2 & 5 & 3.77 & .681 & 4 \\
\hline Bookmarking portals and website related to the field & 148 & 1 & 5 & 3.76 & .846 & 5 \\
\hline Browsing to find references & 148 & 2 & 5 & 3.74 & .741 & 6 \\
\hline Downloading learning materials from portals and websites & 148 & 2 & 5 & 3.68 & .700 & 7 \\
\hline
\end{tabular}

TABLE XXIII.COMPETENCY OF MOBILE TECHNOLOGIES FOR DIGITAL CITIZENSHIP TOOLS

\begin{tabular}{|c|c|c|c|c|c|c|}
\hline Items & $\mathrm{N}$ & Min & Max & Mean & SD & Rank \\
\hline Using other people' works lawfully & 148 & 2 & 5 & 3.36 & .817 & 1 \\
\hline Learning what to do if involved in cyber bullying \& how to overcome & 148 & 2 & 5 & 3.16 & .896 & 2 \\
\hline Expressing myself through digital media & 148 & 2 & 5 & 3.10 & .831 & 3 \\
\hline Creating strong passwords to protect my private information & 148 & 2 & 5 & 3.08 & .829 & 4 \\
\hline Protecting my digital works through the copyright & 148 & 1 & 5 & 2.98 & .742 & 5 \\
\hline Finding out required information & 148 & 1 & 5 & 2.94 & .784 & 6 \\
\hline Evaluating information & 148 & 1 & 5 & 2.91 & .808 & 7 \\
\hline Identifying valuable information & 148 & 1 & 5 & 2.86 & .774 & 8 \\
\hline Using information effectively & 148 & 1 & 5 & 2.79 & .731 & 9 \\
\hline
\end{tabular}

TABLE XXIV. RESUlTS OF MOBILE TECHNOLOGIES AS CREATIVITY AND INNOVATION TOOLS

\begin{tabular}{|c|c|c|c|c|c|c|}
\hline Items & $\mathrm{N}$ & Min & Max & Mean & SD & Rank \\
\hline Uploading work & 148 & 2 & 5 & 3.48 & .778 & 1 \\
\hline Creating an innovation/product & 148 & 2 & 5 & 3.47 & .812 & 2 \\
\hline Producing work & 148 & 2 & 5 & 3.41 & .649 & 3 \\
\hline Performing advanced searches & 148 & 2 & 5 & 3.40 & .687 & 4 \\
\hline Constructing an original work & 148 & 2 & 5 & 3.35 & .648 & 5 \\
\hline
\end{tabular}




\section{CONCLUSIONS AND IMPLICATIONS}

The focus of this study was to report the degree of utilization among first year undergraduate students when using mobile technologies, the level of competency among first year undergraduate students when using mobile technologies, the level of basic operation, communication and collaboration, information Seeking, digital citizenship and creativity and innovation skills in mobile technologies competency separately. The target sample of this study consists of 148 freshmen students majoring in computer science and information technology at Hadhramout University on their level of frequency use of these technologies. This study is unique, and it adds to the body of the research. The uniqueness of this study is due to the few searched topics in this field in the context (Hadhramout). The instrument used to collect the data of the study is adopted from [12] which is quoted from [7] [10] which has been adapted to suit the research objectives.

This study finds that undergraduate students in faculty of computer science and information technology are highly utilizing mobile technologies $(M=151, S D=12.1)$. Similarly, they have good capabilities and skills in using them $(M=141$, $\mathrm{SD}=13.5)$. The results also uncovered that communication is highly used by these students $(\mathrm{M}=41.4, \mathrm{SD}=2.62)$ followed by basic operations $(\mathrm{M}=28.3, \mathrm{SD}=4.02)$. These results of utilization are supported by students' competency in using the same purposes where it is discovered that students are so competent in using mobile technologies for communication $(\mathrm{M}=33.4, \mathrm{SD}=378)$. Moreover, it is revealed that students' skilfulness in basic operation is also significant $(\mathrm{M}=27.4, \mathrm{SD}$ $=3.49$ ).

Through results which shows the second most used purpose is information seeking, it could be implied that students become more aware about getting what will enrich their backgrounds with knowledge in their field. Thus, there must be much focus paid to this method to have better level of students. To have this fulfilled, it is advised that faculty of computer science and information technology to strengthen their bandwidth and permit students to have more access to the internet to encourage them using mobile technologies for that purpose. Moreover, to have a better engagement of students, it is desirable to activate the university application. The use of this application may guide students' choice of information to what is more beneficial and related to their study. Furthermore, activating the app may also elevate the effect of competency in communication uses in which students will be forced to contact only lecturers or classmates. This will result in more engagement and directed communication that will lead to better learning and utilization of mobile technologies.

Despite the significant competency of CS and IT students in basic operation and information seeking, it is preferable that these students acquire more competencies to have higher level of mobile technologies utilization. The author in [8] who declared the importance of students possessing technical skills will assist them in their workforce when graduating, support this assumption. Moreover, they detailed that these skills must be gained prior entering working places, which means HE institutions must empower their students with these skills.
This is achievable through training teaching staff on how to integrate technology into classes. There must be also workshops to provide them with techniques that will enable them directing these learners after arming them with needed capabilities to the desirable uses that will strengthen their skills and make them ready for the work force. This is in a line with [9] which states that education institutions must link their teaching staff to chance that will provide them with technological skills enabling them to have better adoption of continues emerged technologies effectively.

As it can be seen from results that HE undergraduates are utilizing the gadgets for communicating with their friends or family, which means social type of use; therefore, lecturers ought to shift these learners to communicate more for the sake of learning through contacting their lecturers and peers in the campus and other countries. Lecturers must open channels for students to show them how communication can be a good tool with the existence of internet and these mobile technologies. They may innovate through trying the flipping classroom or problem based or any new method of teaching since mobile learning is facilitating these methods a lot.

It is highly recommended since this college is adopting mobile learning method to activate the university app to be a source of knowledge and learning. It is recommended to get use of the app to contain an LMS (learning management system) that will not only help students to register and know their subjects but also communicate and collaborate in different college activities that happened digitally. Moreover, the experience of using M-Learning in this college must be expanded to other colleges to show them the benefits the faculty in outcomes results and learning quality as well.

It is also recommended to conduct this research in another governorate where it might be found more colleges are applying this method. This change will result in having different results since the participants will be greater and the context varied a little bit. It is also recommended to have this study done in qualitative mode where the researcher can get more in depth data about why students choose certain purpose rather the other. With the existence of the app and the website, it is highly recommended to conduct and exploratory study on students and teachers' perspectives towards the existence of these tools in the campus. This study will be like an evaluative study covering strengths and weakness of both tools. Studies must be conducted to check teachers' point of view towards this new method along with whether the infrastructure of the college is supportive or not.

\section{ACKNOWLEDGMENT}

This publication was supported by the Deanship of Scientific Research at Prince Sattam bin Abdulaziz University, Alkharj, Saudi Arabia.

\section{REFERENCE}

[1] Barbaux, M. T. (2006). From lifelong learning to $\mathrm{m}$ learning. Association for Learning Technology, 132.

[2] Corbeil, J. R., \& Valdes-Corbeil, M. E. (2007). Are you ready for mobile learning?. Educause Quarterly, 30(2), 51.

[3] Draugalis, J. R., Coons, S. J., \& Plaza, C. M. (2008). Best practices for survey research reports: a synopsis for authors and reviewers. American journal of pharmaceutical education, 72(1), 11. 
[4] Fraenkel, J. R., Wallen, N. E., \& Hyun, H. H. (2012). Internal validity. How to Design and Evaluate Research in Education. New York: McGraw-Hill, 166-83.

[5] Keller, J. L. (2011). Advancing student success with competency points: Elevating engagement and motivation in community college English composition students. Community College Journal of Research and Practice, 35(6), 484-504.

[6] Lei, J. (2010). Conditions for ubiquitous computing: What can be learned from a longitudinal study. Computers in the Schools, 27(1), 3553.

[7] Mather, C. A., Marlow, A. H., \& Cummings, E. A. (2013). Using Web 2.0 to support Continuing Professional Development of health professionals: Acting locally, engaging globally. In Teaching Matters: Open UTAS to the World (p. 24)।.

[8] Matias, A., \& Wolf, D. F. (2013). Engaging students in online courses through the use of mobile technology. In Increasing Student Engagement and Retention Using Mobile Applications: Smartphones, Skype and Texting Technologies(pp. 115-142). Emerald Group Publishing Limited.

[9] Oblinger, D. G. (2010). a Commitment to Learning: attention, engagement, and the Next generation. Educause Review, 45(5), 4.

[10] Papoutsi, C., \& Drigas, A. S. (2017). Empathy and Mobile Applications. International Journal of Interactive Mobile Technologies, 11(3).
[11] Sedek, M., Mahmud, R., Jalil, H. A., \& Daud, S. M. (2014). Factors influencing ubiquitous technology usage among engineering undergraduates: a confirmatory factor analysis. Middle-East Journal of Scientific Research, 19, 18-27.

[12] Severino, S., \& Messina, R. (2010). Analysis of similarities and differences between on-line and face-to-face learning group dynamics. World Journal on Educational Technology, 2(2), 124-141.

[13] Traxler, J. (2007). Defining, Discussing and Evaluating Mobile Learning: The moving finger writes and having writ.... The International Review of Research in Open and Distributed Learning, 8(2).

[14] Tuparov, G., Alsabri, A. A. A., \& Tuparova, D. (2015, November). Students' readiness for mobile learning in Republic of Yemen-A pilot study. In Interactive Mobile Communication Technologies and Learning (IMCL), 2015 International Conference on (pp. 190-194). IEEE.

[15] World Bank Group. (2016). World development report 2016: digital dividends. World Bank Publications.

[16] Oinas-Kukkonen, H., \& Harjumaa, M. (2008, June). A systematic framework for designing and evaluating persuasive systems. In International conference on persuasive technology (pp. 164-176). Springer, Berlin, Heidelberg.

[17] Liaw, S. S., Hatala, M., \& Huang, H. M. (2010). Investigating acceptance toward mobile learning to assist individual knowledge management: Based on activity theory approach. Computers \& Education, 54(2), 446-454. 